\title{
JBIR-12, a novel antioxidative agent from Penicillium sp. NBRC 103941
}

\author{
Miho Izumikawa ${ }^{1}$, Aya Nagai $^{1}$, Takayuki Doi $^{2}$, Motoki Takagi ${ }^{1}$ and Kazuo Shin-ya ${ }^{3}$ \\ In the course of our screening program for active compounds from fungal metabolites, we isolated JBIR-12 (1) as a free radical \\ scavenger from the culture broth of Penicillium sp. NBRC 103941. Structure elucidation of 1 was carried out using methylated \\ and/or acetylated derivatives of 1 . As a consequence, the structure of 1 was determined to be a novel highly oxygenated \\ tetrahydronaphthalene species attached to an acyl chain moiety on the basis of NMR and other spectroscopic data. It was \\ interesting that 1 was spontaneously methylated when left in methanol. Furthermore, isomerization or rearrangements could \\ occur during the derivatization of 1 . Compound 1 exhibited potent radical scavenging activity against 1,1-diphenyl-2- \\ picrylhydrazyl radical with an $\mathrm{IC}_{50}$ value of $75 \mu \mathrm{m}$.
}

The Journal of Antibiotics (2009) 62, 177-180; doi:10.1038/ja.2009.13; published online 27 February 2009

Keywords: antioxidative agent; JBIR-12; Penicillium sp.; radical scavenging

\section{INTRODUCTION}

Free radicals play a causative role in many disease states including atherosclerosis, inflammation, ischemia-reperfusion injury, rheumatism and central nervous diseases. ${ }^{1}$ In addition, senility and cancer initiation as well as progression are also believed to involve active oxygen species. ${ }^{2}$ In fields of such diseases, an effective antioxidant could be a useful lead compound for the development of a clinically useful drug. Historically, Penicillium species have been shown to be producers, with more than 900 bioactive compounds documented. ${ }^{3}$ Furthermore, the important pharmaceutical agents, penicillin (antibiotic) and compactin (lipidlowering agent), were isolated from Penicillium spp. Therefore, we carried out the screening for antioxidants from culture broths of Penicillium species.

In the course of our screening program from metabolites of Penicillium spp., we isolated a novel antioxidative agent, designated as JBIR-12 (1), from the culture broth of Penicillium sp. NBRC 103941. The structure of $\mathbf{1}$ contains highly oxygenated tetrahydronaphthalene moiety possessing an acyl chain, and shows unique chemical features. This paper describes the fermentation, isolation, physico-chemical properties, structure elucidation and biological activity of $\mathbf{1}$ as well as a hypothetical reaction mechanism of the addition of methanol to 1 .

\section{RESULTS AND DISCUSSION}

Isolation

The culture $(100-\mathrm{ml}$ Erlenmeyer flask $\times 20)$ was extracted with $80 \% \mathrm{Me}_{2} \mathrm{CO}(400 \mathrm{ml})$. The extract was evaporated in vacuo, and the residual aqueous concentrate was extracted with EtOAc $(100 \mathrm{ml} \times 3)$. After drying over $\mathrm{Na}_{2} \mathrm{SO}_{4}$, the organic layer was evaporated to dryness. The dried residue $(1.87 \mathrm{~g})$ was chromatographed on normal-phase medium-pressure liquid chromatography (Purif-Pack SI-60; Moritex, Tokyo, Japan) with an $n$-hexane-EtOAc linear gradient system $(0-100 \%$ EtOAc), and fractions including major metabolites were collected by LC-MS monitoring. The eluate (70-100\% EtOAc, $720 \mathrm{mg}$ ) was further separated by a reversed-phase flash column (Purif-Pack ODS-100; Moritex) with an $\mathrm{H}_{2} \mathrm{O}-\mathrm{MeOH}$ linear gradient system $(50-100 \% \mathrm{MeOH})$ to yield a major fraction $(80-100 \% \mathrm{MeOH}$, $276 \mathrm{mg}$ ). This eluate was subjected to preparative reversed-phase HPLC developed with $60 \%$ aqueous MeCN containing $0.2 \%$ formic acid (flow rate: $10 \mathrm{ml} \mathrm{min}^{-1}$ ) to yield $\mathbf{1}$ (Rt $9.8 \mathrm{~min}, 26.1 \mathrm{mg}$ ).

\section{Structure elucidation}

The physico-chemical properties of $\mathbf{1}$ are summarized in Table 1. Compound 1 was isolated as a red powder and had the molecular formula $\mathrm{C}_{24} \mathrm{H}_{28} \mathrm{O}_{8}$ revealed by HR-ESI-MS data $(\mathrm{m} / z 443.1694$ $\left.(\mathrm{M}-\mathrm{H})^{-}, \Delta-1.2 \mathrm{mmu}\right)$. The structure of 1 was established mainly

\footnotetext{
${ }^{1}$ Biomedicinal Information Research Center (BIRC), Japan Biological Informatics Consortium (JBIC), Koto-ku, Tokyo, Japan; ${ }^{2}$ Graduate School of Pharmaceutical Sciences, Tohoku University, Aoba-ku, Sendai, Japan and ${ }^{3}$ Biomedicinal Information Research Center (BIRC), National Institute of Advanced Industrial Science and Technology (AIST), Koto-ku, Tokyo, Japan

Correspondence: Dr K Shin-ya, Biomedicinal Information Research Center (BIRC), National Institute of Advanced Industrial Science and Technology (AIST), 2-42 Aomi, Koto-ku, Tokyo 135-0064, Japan.

E-mail: k-shinya@aist.go.jp or Dr M Takagi, Biomedicinal Information Research Center (BIRC), Japan Biological Informatics Consortium (JBIC), 2-42 Aomi, Koto-ku, Tokyo 135-0064, Japan.

E-mail: motoki-takagi@aist.go.jp

Received 4 November 2008; revised 31 January 2009; accepted 2 February 2009; published online 27 February 2009
} 
by NMR analyses of $\mathbf{1}$ and its chemically modified derivative $\mathbf{3}$ as follows:

The direct connectivity between protons and carbons was established by the HSQC (heteronuclear single-quantum coherence) spectrum, and the tabulated ${ }^{13} \mathrm{C}$ and ${ }^{1} \mathrm{H}$ NMR spectral data for $\mathbf{1}$ are shown in Table 2. The ${ }^{1} \mathrm{H}_{-}{ }^{1} \mathrm{H}$ DQF (double-quantum filtered)-COSY and HMBC (heteronuclear multiple bond correlation) spectra established two partial structures (Figure 1). The combination of proton coupling constants and ${ }^{1} \mathrm{H}-{ }^{1} \mathrm{H}$ correlations in the ${ }^{1} \mathrm{H}-{ }^{1} \mathrm{H}$ DQF-COSY constructed an acyl chain substructure as shown in Figure 1. The sequence from $2^{\prime}-\mathrm{H}\left(\delta_{\mathrm{H}} 5.99\right)$ to $10^{\prime}-\mathrm{H}\left(\delta_{\mathrm{H}} 0.88\right)$ through $3^{\prime}-\mathrm{H}\left(\delta_{\mathrm{H}}\right.$ $7.36), 4^{\prime}-\mathrm{H}\left(\delta_{\mathrm{H}} 6.37\right), 5^{\prime}-\mathrm{H}\left(\delta_{\mathrm{H}} 6.67\right), 6^{\prime}-\mathrm{H}\left(\delta_{\mathrm{H}} 6.20\right), 7^{\prime}-\mathrm{H}\left(\delta_{\mathrm{H}} 5.88\right)$, $8^{\prime}-\mathrm{H}\left(\delta_{\mathrm{H}} 2.14\right)$ and $9^{\prime}-\mathrm{H}\left(\delta_{\mathrm{H}} 1.37\right)$, in addition to a spin coupling between $8^{\prime}-\mathrm{H}$ and $11^{\prime}-\mathrm{H}\left(\delta_{\mathrm{H}} 1.03\right)$, established the branched alkyl chain moiety. The proton spin coupling constants between $2^{\prime}-\mathrm{H}$ and $3^{\prime}-\mathrm{H}(J=15.3 \mathrm{~Hz}), 4^{\prime}-\mathrm{H}$ and $5^{\prime}-\mathrm{H}(J=14.8 \mathrm{~Hz})$, and $6^{\prime}-\mathrm{H}$ and $7^{\prime}-\mathrm{H}$ $(J=15.2 \mathrm{~Hz})$, together with the ${ }^{1} \mathrm{H}_{-}{ }^{13} \mathrm{C}$ long-range correlations from $2^{\prime}-\mathrm{H}$ and $3^{\prime}-\mathrm{H}$ to $\mathrm{C}-1^{\prime}\left(\delta_{\mathrm{C}} 166.8\right)$, revealed a $(2 E, 4 E, 6 E)-8$-methyldeca2,4,6-trienoate moiety as shown in Figure 1a.

Oxygenated methylene protons $13-\mathrm{H}\left(\delta_{\mathrm{H}} 5.08,4.68\right)$, were ${ }^{1} \mathrm{H}-{ }^{13} \mathrm{C}$ long-range coupled to C-5 $\left(\delta_{\mathrm{C}} 121.6\right), \mathrm{C}-6\left(\delta_{\mathrm{C}} 128.2\right)$ and $\mathrm{C}-7\left(\delta_{\mathrm{C}}\right.$ $146.3)$. An aromatic proton, $9-\mathrm{H}\left(\delta_{\mathrm{H}} 7.22\right)$, was $m$-coupled to $\mathrm{C}-5$ and $\mathrm{C}-7$ in the HMBC spectrum of $\mathbf{1}$. Thus, the hydroxymethyl group was deduced to be substituted at the position of C-6. Long-range couplings from $9-\mathrm{H}$ to $\mathrm{C}-8\left(\delta_{\mathrm{C}} 153.1\right)$ and C-10 $\left(\delta_{\mathrm{C}} 140.4\right)$, together with the ${ }^{13} \mathrm{C}$ chemical shifts at C-7 and C-8, established the assignments of a benzene ring moiety. A methyl proton, 11- $\mathrm{H}\left(\delta_{\mathrm{H}} 1.60\right)$, was longrange coupled to $\mathrm{C}-1\left(\delta_{\mathrm{C}} 76.2\right), \mathrm{C}-2\left(\delta_{\mathrm{C}} 206.7\right)$ and $\mathrm{C}-10$. In the same manner, a methyl proton, $12-\mathrm{H}\left(\delta_{\mathrm{H}} 1.54\right)$, was long-range coupled to C-2, C-3 $\left(\delta_{\mathrm{C}} 85.5\right)$ and C-4 $\left(\delta_{\mathrm{C}} 194.1\right)$. In addition, a long-range coupling was observed between the aromatic proton $9-\mathrm{H}$ and $\mathrm{C}-1$, which indicated that $\mathrm{C}-1$ was located at the peri position of 9-H. Thus, highly oxygenated tetrahydronaphthalene moiety was determined as shown in Figure 1b.

Table 1 Physico-chemical properties of 1

\begin{tabular}{ll}
\hline Appearance & Red powder \\
\hline Melting point & $47-49{ }^{\circ} \mathrm{C}$ \\
{$[\alpha]_{D}^{23}(\mathrm{MeOH})$} & $-278.4^{\circ}(c 0.32)$ \\
Molecular formula & $\mathrm{C}_{24} \mathrm{H}_{28} \mathrm{O}_{8}$ \\
HRESIMS $(\mathrm{m} / \mathrm{z})$ & \\
& Found: 443.1694 [M-H] $]^{-}$ \\
& Calcd: 443.1706 \\
UV $\lambda_{\max }(\mathrm{MeOH}) \mathrm{nm}(\varepsilon)$ & $310(45330), 244(14330)$ \\
IR $v_{\max }(\mathrm{KBr}) \mathrm{cm}^{-1}$ & $1684,1612,1302,1134,1086,1005$ \\
\hline
\end{tabular}

To establish the substituted position of the acyl chain moiety of $\mathbf{1}$, chemical modification was carried out as follows: Treatment of $\mathbf{1}$ with methyl iodide and potassium carbonate in DMF afforded a $(7,8,13)$ $\mathrm{O}$-trimethyl-JBIR-12 (2) as a main derivative. Each ${ }^{1} \mathrm{H}_{-}{ }^{13} \mathrm{C}$ long-range correlation from methoxyl groups 7-OMe, 8-OMe and 13-OMe to C-7, C-8 and C-13, respectively, deduced substituted position of their methoxyl groups. Only one hydroxyl group at C-1 could not be methylated, and then 2 was acetylated by acetic anhydride in pyridine to give a $(7,8,13)$-O-trimethyl-1-O-acetyl-JBIR-12 (3). NOEs between $9-\mathrm{H}$ and $11-\mathrm{H}$, and $9-\mathrm{H}$ and methyl proton at acetyl residue revealed

Table $2{ }^{13} \mathrm{C}(125 \mathrm{MHz})$ and ${ }^{1} \mathrm{H}(500 \mathrm{MHz})$ NMR data for 1 in $\mathrm{CD}_{3} \mathrm{OD}$ and ${ }^{13} \mathrm{C}(150 \mathrm{MHz})$ and ${ }^{1} \mathrm{H}(600 \mathrm{MHz}) \mathrm{NMR}$ data for 3 in $\mathrm{CDCl}_{3}$

\begin{tabular}{|c|c|c|c|c|}
\hline \multirow[b]{2}{*}{ No. } & \multicolumn{2}{|r|}{1} & \multicolumn{2}{|r|}{3} \\
\hline & $\delta_{C}$ & $\delta_{H}$ (multiplicity, $J=H z$ ) & $\delta_{C}$ & $\delta_{H}$ (multiplicity, $J=H z$ ) \\
\hline 1 & 76.2 & & 81.3 & \\
\hline 2 & 206.7 & & 200.4 & \\
\hline 3 & 85.5 & & 84.9 & \\
\hline 4 & 194.1 & & 191.7 & \\
\hline 5 & 121.6 & & 122.7 & \\
\hline 6 & 128.2 & & 133.2 & \\
\hline 7 & 146.3 & & 148.4 & \\
\hline 8 & 153.1 & & 157.0 & \\
\hline 9 & 112.6 & $7.22(\mathrm{~s})$ & 105.6 & $6.81(\mathrm{~s})$ \\
\hline 10 & 140.4 & & 140.3 & \\
\hline 11 & 33.6 & $1.60(\mathrm{~s})$ & 31.8 & $1.85(\mathrm{~s})$ \\
\hline 12 & 24.0 & $1.54(\mathrm{~s})$ & 24.6 & $1.75(\mathrm{~s})$ \\
\hline \multirow[t]{2}{*}{13} & 57.7 & $5.08(d, 12.5)$ & 64.3 & $4.99(d, 9.7)$ \\
\hline & & $4.68(d, 12.5)$ & & $4.56(d, 9.7)$ \\
\hline $1^{\prime}$ & 166.8 & & 165.1 & \\
\hline $2^{\prime}$ & 119.0 & $5.99(d, 15.3)$ & 119.0 & $5.98(d, 15.3)$ \\
\hline $3^{\prime}$ & 148.3 & $7.36(\mathrm{dd}, 15.3,11.3)$ & 143.0 & $7.36(d d, 15.3,11.5)$ \\
\hline $4^{\prime}$ & 129.0 & $6.37(\mathrm{dd}, 14.8,11.3)$ & 127.8 & $6.26(\mathrm{dd}, 14.8,11.5)$ \\
\hline $5^{\prime}$ & 144.0 & $6.67(\mathrm{dd}, 14.8,10.8)$ & 142.3 & $6.53(\mathrm{dd}, 14.8,10.7)$ \\
\hline $6^{\prime}$ & 129.8 & $6.20(d d, 15.2,10.8)$ & 128.2 & $6.12(d d, 15.2,10.7)$ \\
\hline $7^{\prime}$ & 147.9 & $5.88(d d, 15.2,8.1)$ & 146.8 & $5.81(\mathrm{dd}, 15.2,7.9)$ \\
\hline $8^{\prime}$ & 40.2 & $2.14(\mathrm{~m})$ & 38.8 & $2.14(\mathrm{~m})$ \\
\hline $9^{\prime}$ & 30.6 & $1.37(\mathrm{dq}, 7.4,1.2)$ & 29.5 & $1.35(\mathrm{dq}, 7.3,1.2)$ \\
\hline $10^{\prime}$ & 12.2 & $0.88(t, 7.4)$ & 11.7 & $0.87(t, 7.3)$ \\
\hline $11^{\prime}$ & 20.3 & $1.03(d, 6.9)$ & 19.7 & $1.02(\mathrm{~d}, 6.7)$ \\
\hline 1-OAc, Me & & & 20.8 & $2.19(\mathrm{~s})$ \\
\hline $\mathrm{C}=\mathrm{O}$ & & & 169.1 & \\
\hline 7-OMe & & & 61.8 & $3.85(\mathrm{~s})$ \\
\hline 8-OMe & & & 55.9 & $3.93(\mathrm{~s})$ \\
\hline 13-OMe & & & 58.6 & $3.34(\mathrm{~s})$ \\
\hline
\end{tabular}

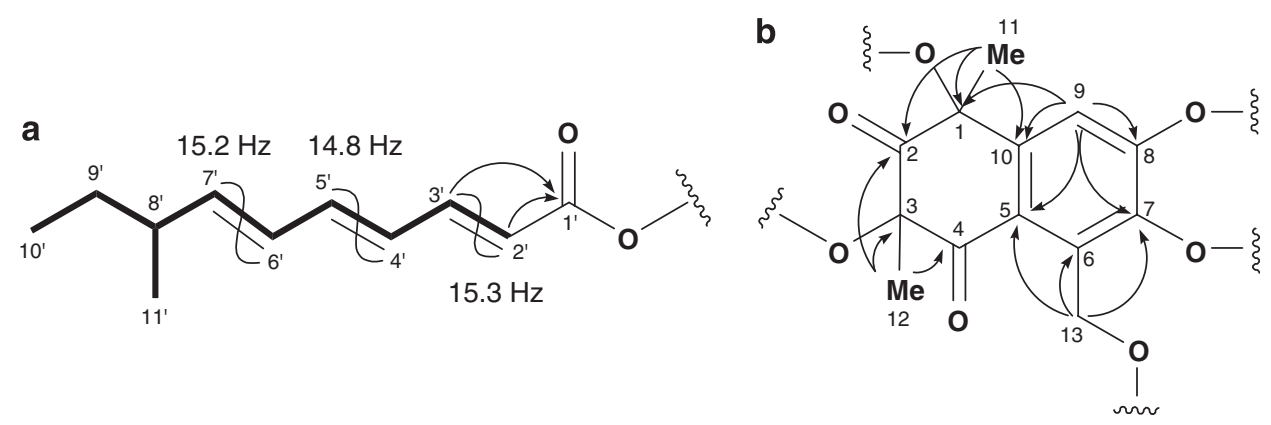

Figure $1{ }^{1} \mathrm{H}^{-1} \mathrm{H}$ (bold line) and main ${ }^{1} \mathrm{H}^{13} \mathrm{C}$ (arrows) correlations in 2D NMR of 1. 


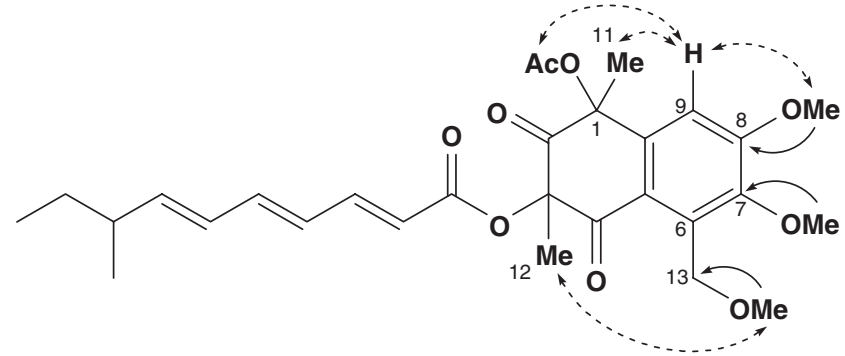

Figure 2 Key ${ }^{1} \mathrm{H}_{-}{ }^{13} \mathrm{C}$ (arrows) and NOESY (dashed arrows) correlations in 2D NMR of 3.<smiles>CCC(F)/C=C/C=C/C=C/C(=O)OC1C(=O)c2c(cc(O)c(O)c2CO)C(O)(I)C1=O</smiles>

Figure 3 Structure of JBIR-12 (1). that the acyl chain moiety is substituted at the position of C-3 by an ester bond (Figure 2). Thus, the total structure of $\mathbf{1}$ was elucidated as shown in Figure 3.

During NMR experiments of 1 in methanol- $d_{4}$, we observed the appearance of some extra signals corresponding to deuteride methoxyl groups. The LC-MS analyses of this sample indicated that 1 was changed to deuterium labeled mono- or di-O-methyl compounds. Hence, we speculated that this reaction occurred by a subsequent process. The hydroxyl group at C-13 in 1 was first displaced with a methoxyl group in $\mathrm{MeOH}$. Further displacement of the hydroxyl group at C-7 with a methoxyl group gradually occurred. Considering into these results, dehydration at C-13 could be accompanied by 1,4addition of $\mathrm{MeOH}$ or 1,2- and 1,4-addition of $\mathrm{MeOH}$ through a hypothetical scheme as shown in Figure 4. Furthermore, 1 might be isomerized or rearranged during a derivatization to $\mathbf{2}$, as acylation of $\mathbf{2}$ afforded several minor congeners, of which some methoxyl signals were recognized in its ${ }^{1} \mathrm{H}$ NMR spectrum. Therefore, we could not determine the relative stereochemistry at $\mathrm{C}-1$ and $\mathrm{C}-3$, although an NOE between the methyl proton of the acetyl group and the methyl proton 12-H was observed. This compound seems to keep its structure intact on subtle electron translocation balance. Therefore, $\mathbf{1}$ is quite an interesting target for total synthesis, which is desired to establish its stereochemistry.

Biosynthetically, $\mathbf{1}$ is hypothetically produced through the combination of two different pathways. We speculated that $(2 E, 4 E, 6 E)-8$ -<smiles></smiles><smiles>[M]C1([R6])C(=O)c2c(cc(O)c(O)c2COC)C(C)(O)C1=O</smiles>

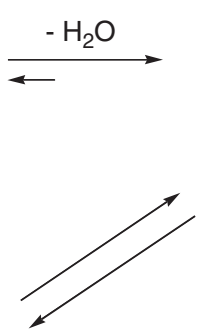<smiles>C=C1C2=C(C=C(O)C1(C)O)C(C)(O)C(=O)C(C)(OC(C)=O)C2=O</smiles><smiles>C#CCOCc1c(OC)c(O)cc2c1C(=O)C(C)(O)C(=O)C2(C)O</smiles>

Figure 4 Methylation mechanism at 13-OH and 7-OH. 
methyldeca-2,4,6-trienoate moiety is biosynthesized by type-I polyketide synthase, and an oxygenated tetrahydronaphthalene moiety comes from a fungal 1,8-dihydronaphthalene (DHN)-melanin pathway., ${ }^{4,5}$ The highly oxygenated and methylated tetrahydronaphthalene moiety and $(2 E, 4 E, 6 E)$-8-methyldeca-2,4,6-trienoate moiety are connected through an ester bond. Studies on detailed biosynthetic pathway require further labeling and genetic experiments.

\section{Biological activity}

We evaluated 1,1-diphenyl-2-picrylhydrazyl (DPPH) radical scavenging activity by 1 . Compound 1 exhibited DPPH radical scavenging activity with an $\mathrm{IC}_{50}$ value of $75 \mu \mathrm{M}$, which was almost the same activity as that of $\alpha$-tocopherol $\left(\mathrm{IC}_{50}=50 \mu \mathrm{M}\right)$. The structure of 1 involves phenolic hydroxyl groups, which are considered to play a significant role in expressing radical scavenging activity. Actually, the derivatives $\mathbf{2}$ and $\mathbf{3}$ did not show any radical scavenging activity at the concentration of $200 \mu \mathrm{m}$. Studies on detailed biological activities are now underway.

\section{METHODS}

\section{General experimental procedures}

Melting point was determined with a Yanagimoto micro melting point apparatus (Yanagimoto, Kyoto, Japan). Optical rotations were operated on a SEPA-300 polarimeter (Horiba, Kyoto, Japan). HR-ESI (electrospray ionization)-MS data were recorded on an LCT-Premier XE mass spectrometer (Waters, Milford, MA, USA). UV and IR spectra were measured on a U-3200 spectrophotometer (Hitachi, Tokyo, Japan) and an FT-720 spectrophotometer (Horiba), respectively. NMR spectra were recorded on an NMR System 600 or 500 NB CL (Varian, Palo Alto, CA, USA). Chemical shifts are reported in p.p.m. relative to chloroform (7.26 p.p.m. for ${ }^{1} \mathrm{H}$ ) or chloroform-d (77.0 p.p.m. for ${ }^{13} \mathrm{C}$ ), and methanol (3.30 p.p.m. for ${ }^{1} \mathrm{H}$ ) or methanol- $d_{4}$ (49.0 p.p.m. for $\left.{ }^{13} \mathrm{C}\right)$. Normal- and reversed-phase medium-pressure liquid chromatography was performed on a Purif-Pack SI-60 (Moritex) and a Purif-Pack ODS-100 (Moritex), respectively. Preparative reversed-phase HPLC was carried out on a Senshu Pak PEGASIL ODS $(20$ i.d. $\times 150 \mathrm{~mm}$; Senshu Scientific, Tokyo, Japan) with detection by a 2996 photodiode array detector (Waters) and a 3100 mass detector (Waters). Reagents and solvents were of the highest grade available.

\section{Microorganism}

Penicillium sp. NBRC 103941 was purchased from the National Institute of Technology and Evaluation (NITE; Tokyo, Japan)

\section{Medium and fermentation}

The seed medium, potato dextrose, was composed of $2.4 \mathrm{gl}^{-1}$ Potato Dextrose Broth (BD Biosciences, San Jose, CA, USA). The production medium consisted of $3 \mathrm{~g}$ of brown rice (Hitomebore, Miyagi, Japan), $6 \mathrm{mg}$ of Bacto-Yeast extract (BD Biosciences), $3 \mathrm{mg}$ of sodium tartrate, $3 \mathrm{mg} \mathrm{K \textrm {H } _ { 2 }} \mathrm{PO}_{4}$ and $9 \mathrm{ml}$ of $\mathrm{H}_{2} \mathrm{O}$ in a 100-ml Erlenmeyer flask.
Penicillium sp. NBRC 103941 was cultivated in 50-ml test tubes containing $15 \mathrm{ml}$ of a seed medium. The test tubes were shaken on a reciprocal shaker ( 355 r.p.m.) at $27^{\circ} \mathrm{C}$ for 3 days. Aliquots $(5 \mathrm{ml}$ ) of the culture were transferred to $100-\mathrm{ml}$ Erlenmeyer flasks containing the production medium and incubated in static culture at $27^{\circ} \mathrm{C}$ for 14 days.

\section{Methylation and acetylation}

Compound $1(1.1 \mathrm{mg})$ was dissolved in $250 \mu \mathrm{l}$ of DMF, mixed with $0.2 \mathrm{mg}$ of $\mathrm{K}_{2} \mathrm{CO}_{3}$ and $25 \mu \mathrm{l}$ of methyl iodide and stirred at room temperature overnight. The mixture was diluted with $\mathrm{MeOH}$, evaporated in vacuo and applied to preparative reversed-phase HPLC using a PEGASIL-ODS (Senshu Pak, 20 i.d. $\times 150 \mathrm{~mm}$ ) developed with $80 \%$ aqueous $\mathrm{MeOH}$ containing $0.1 \%$ formic acid (flow rate: $\left.10 \mathrm{ml} \mathrm{min}^{-1}\right)$ to give $(7,8,13)$-O-trimethyl JBIR-12 (2, Rt $13.0 \mathrm{~min}$, $0.5 \mathrm{mg})$. The structure of 2 was confirmed by LC-MS and NMR analyses.

Compound $2(0.5 \mathrm{mg})$ was dissolved in $200 \mu \mathrm{l}$ of pyridine, mixed with $20 \mu \mathrm{l}$ of acetic anhydride and stirred at room temperature overnight. The mixture was diluted with $\mathrm{H}_{2} \mathrm{O}$, extracted with EtOAc and the organic extract was evaporated in vacuo. This extract was applied to preparative reversed-phase HPLC (Senshu Pak PEGASIL-ODS, 20 i.d. $\times 150 \mathrm{~mm}$ ) developed with $85 \%$

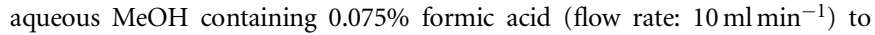
yield (7,8,13)-O-trimethyl-1-O-acetyl-JBIR-12 (3, Rt $11.5 \mathrm{~min}, \quad 0.4 \mathrm{mg}$, $\left.\mathrm{C}_{29} \mathrm{H}_{36} \mathrm{O}_{9}, m / z 529.2438(\mathrm{M}+\mathrm{H})^{+}, \Delta 0 \mathrm{mmu}\right)$. The structure of 3 was established by NMR analyses (Table 2).

\section{DPPH radical scavenging activity}

A 96-well multiplate was used for the DPPH radical scavenging assay. ${ }^{6}$ Compound $\mathbf{1}$ and $\alpha$-tocopherol as a positive control were dissolved in $\mathrm{MeOH}$ to prepare samples of $1 \mathrm{~mm}$, before being diluted with $\mathrm{MeOH}$ to prepare samples of a linear concentration system of $0.01-0.5 \mathrm{~mm}$. A volume of $90 \mu \mathrm{l}$ of $200 \mu \mathrm{M}$ DPPH dissolved in $\mathrm{MeOH}$ and $10 \mu \mathrm{l}$ of sample were mixed in the microplate. After $1 \mathrm{~h}$ incubation at room temperature, the absorbance was measured at $540 \mathrm{~nm}$.

\section{ACKNOWLEDGEMENTS}

This work was supported by a grant from the New Energy and Industrial Technology Department Organization (NEDO) of Japan.

1 Hammond, B., Kontos, A. \& Hess, M. L. Oxygen radicals in the adult respiratory distress syndrome, in myocardial ischemia and reperfusion injury, and in cerebral vascular damage. Can. J. Physiol. Pharmacol. 63, 173-187 (1985).

2 Finkel, T. Radical medicine: treating ageing to cure disease. Nat. Rev. Mol. Cell Biol. 6, 971-976 (2005).

3 Bérdy, J. Bioactive microbial metabolites. J. Antibiot. 58, 1-26 (2005).

4 Wheeler, M. H. \& Bell, A. A. Melanins and their importance in pathogenic fungi. In Current Topics in Medical Mycology Vol. 2. (ed. McGinnis, M.R.) 338-387 (SpringerVerlag, New York, NY, 1988).

5 Tsai, H. F., Wheeler, M. H., Chang, Y. C. \& Kwon-Chung, K. J. A developmentally regulated gene cluster involved in conidial pigment biosynthesis in Aspergillus fumigatus. J. Bacteriol. 181, 6469-6477 (1999)

6 Wang, G. J., Lin, S. Y., Wu, W. C. \& Hou, W. C. DPPH radical scavenging and semicarbazide-sensitive amine oxidase inhibitory and cytotoxic activities of Taiwanofungus camphoratus (Chang-chih). Biosci. Biotechnol. Biochem. 71, 1873-1878 (2007). 